\title{
The Innovation in The Form of Crowd- Sourcing That Modern Communication Technologies and The Online Individual Brought to Journalism Practices
}

\author{
Kaya S. ${ }^{1}$ \\ ${ }^{1}$ Sertaç KAYA, İstanbul Aydın University, Turkey \\ e-mail: sertackaya1@aydin.edu.tr
}

\begin{abstract}
The internet brought along a lot of innovations by entering our lives and bringing the social networks into use for the people. Newspapers and journalists are obliged to update themselves through change and transformation appropriate to these new environments. These innovations introduced the concept of networked journalism. The journalism that is trying to integrate itself into these areas found a field where it interacts with the reader/user. Users who benefit from the new communication technologies' opportunity are no longer only consuming the information but are also producing them at the same time. User generated contents shows us that these people who are connected to the networks play a more active role. At the same time with crowd-sourcing this activity has brought participation and cooperation in news production processes. The aim of this study is to present the characteristics of the terms networked journalism, user generated content and crowdsourcing, which were introduced to us by the internet and social media, with a literature survey and is to discuss its effects on journalism via the example of The Guardian.
\end{abstract} Sourcing

Keywords: Internet, Social Media, Networked Journalism, User Generated Contents, Crowd-

\section{Introduction}

Advances in the field of communication have led to innovations in the self-expression of individuals and in the interaction with other people. The introduction of the Internet into the use of ordinary citizens, then Web 2.0, followed by the establishment of the sites so-called social media, a significant part of the world's population has been included in these networks. Any place which provides internet connection through a fixed computer or smartphones, people have the opportunity to see and comment on events online whenever or whatever they want. At home, at work, or on the streets, in all areas that people spend their lives, they have found the opportunity to be able to transfer their ideas, feelings, what they saw or experienced through these devices to others.

These developments have resulted in important changes in many occupational groups as well as in the field of journalism. Internet-based technology innovations have pushed organizations such as newspaper, television, radio which are located on the mainstream media to make themselves a place on web. Thus, traditional media devices, which have to change and transform themselves according to these channels, have begun to be reshaped under the inclusion of the Internet which is a new communication tool.

As we look in terms of journalistic practices, it can be seen that many new formats and new approaches are being implemented. Beside continuing publication in print, they began to reach their readers via their websites, not only through text but also through the opportunity to add supplementary elements for news such as audio, video and graphics. Nevertheless, the space limit on the paper, the fast consumption and aging of the news are now history. Newspapers have made it possible to update the news instantly along with their websites, to add new news, and allow readers to participate in the news with comments, information and documents online. 
Also, in social media, news and information are provided to readers / users via their own accounts. The way in which the traditional media uses social media is usually by transmitting news from their accounts and by having people's attention to their websites through links to transfer the news. Here, people have also the chance to comment on the news and provide an interactive environment with instant feedback.

\section{A Brief Look at Internet and Social Media}

Internet is a global network system which uses protocols such as TCP/IP to transmit data through a variety of media types. Internet and World Wide Web terms are often used interchangeably, but they are not exactly the same thing. Because while the internet is referring to the global communication system including hardware and infrastructure, the web is one of the services transmitted through the internet (url1).

For Web 1.0 we can say that it represents the beginning period of internet. On Web 1.0 a small number of authors, would create web pages for many readers. The usage structure provided an opportunity for people to obtain information directly from a source (Naik and Shivalingaiah, 2009: 2). So, the possibilities of the web's first usage opportunities only allowed us to search and read information. User interaction or content contribution was minimal (url2). That is why Web 1.0 is described only as reading (read-only). The Internet has exceedingly presented a new world to people and attracted lots of attention. As interest increased, Web 1.0 failed to meet the demands, was seen to be inadequate and its flaws began to emerge. The fact that the sites could only be viewed by the users and that it is not open to any intervention has revealed that it remained very static.

Web 2.0 is the ability to contribute to the content and interact with other web users. The appearance of web has significantly changed in a short time with the ability to interfere to content by user and the ability to interact with other subscribers (url2). It even brought up another way of connecting the world with one another, allowing information to be gathered and shared effectively. In fact, Web 2.0 is an idea of the reciprocity between the user and the provider that is highlighted (Naik and Shivalingaiah, 2009: 3). Here, the usage of read-only definition for Web 1.0 is replaced as selfreading and writing (read-write). From the unidirectional period of Web 1.0, where people had the access to the web sites to read a text which is fixed and unchangeable, we switched to the Web 2.0 period where updates are often done and a interactive and participatory environment is created. Through social media tools like social networks, blogs and wiki offered to us it provided millions of people to get in contact with each other. An environment open to people's feedback is created on the networks where all the visual, auditory and written materials are used at the same time.

Social media can be explained as online communities that allow users to connect and communicate with others, to share personal content as well as building up a network for their own. (Kara, 2012: 115). Social media, is a type of media determining its own agenda, having its own rules and communication style and being more participatory and more active. (Gündüz and Pembecioğlu, 2013: 321).

Özçağlayan and Uyanık state that social media can be defined as "the platforms and social environments formed by people for sharing, reading and exploring news, information and content through the interactive communication process from one person to more as well as from more people to more people." Noting that the important point is the "interaction" and "sharing", in this case, they state: "Traditional mass communication tools, intended to the mass of audience are quite different from the one-sided flow of communication, indicates a new process which consists of the active participation of an user" (2010: 2).

Danah Boyd and Nicole Ellison describe social networking sites as web-based services which allow the individuals; (1) to create a profile, public or semi-public inclusive of a limited system, (2) to list other users' profiles which they are connected in this system (3) to look at the lists of links created by their own or other users in the system and to follow them (2008: 221). Many sites are included in the networks we define as social media and these sites provide users on the one hand the opportunity to search for the content they want to reach, on the other hand it provides sharing opportunities within the interaction. However, people who have been stripped of time and space limitations have been able to communicate with each other very easily through networks. 
Social networks allow the users to share photo, video, music and text, to save and like other users' posts, to follow users included in the network, and to communicate with them. These kinds of sharing enable people to express themselves, to learn different subjects from others and to give other users and friends advices.

\section{Networked Journalism and User Generated Content as Supporters of Crowd- Sourcing}

It is said that the emergence of new tools and practices have led to the redefinition of both journalism professionalism and the path of knowledge production in this new information system.

In the digital environment where journalists work, the integration of more mass feedback, the hearing of more sound, the presenting of more different perspectives on same news, the archive for longer periods and the availability of more searchable stories, the dealing of the world's changes more actively by more people by taking photographs or videos of the important moments, commenting on blogs or sharing important stories associated with them is revealing new facts (Haake, Parks and Castells, 2012: 2923). Thus, Networked Journalism is a concept that has emerged because journalists using these new tools to do their jobs. Interaction with other people in the networks, the help received from them, brings a great difference in terms of obtaining the knowledge and conveying it.

Networked journalism is based on the capacity to disseminate, share and save the information. Today the quality of journalism being often in cooperation with people of various professions and citizens, includes the validation of knowledge and finally, the networks that reveal the essence of the story. (Haak, Parks and Castells, 2012: 2927). While some old-fashioned journalism perceptions are left behind within this period, collecting information via networks and presenting it after making it meaningful is gaining more importance.

Today, journalists have left behind the period of completing their works by transforming the information on hand into news. The news in the main stream which received no feedback and static news flows which were not updated have entered a new era through networks. In this new era, journalists are free to contact with people directly and use them as a resource, being able to follow their news by interacting with the reader and often being able to share an information.

Charlie Beckett, on the other hand, says that what he means by networked journalism is the synthesis of traditional news journalism with the new forms of participatory media such as mobile phones, e-mails, web sites, blogs, micro blogs and social networks brought by Web 2.0 technology. Networked journalism enables people to be involved in all areas of journalism through crowd-sourcing, interaction, hyperlinks, user-generated content, and forums. It transforms the creation of news into a top-down collaborative process. Networked journalism creates a new relationship between the journalist, the story and the community. The news is no longer a product that is being left on the doormats or is being activated from the remote control. Because it changed from being a linear process into a versatile interaction. Thus, news today has become a service industry which forms the flow, analyse and interpretation of information (2010: 1-3). In other words, journalism is becoming a reconstructed process on the basis of interaction. This structure supported by technology and individuals constitutes the main structure of the networked journalism approach.

Web 2.0 technologies provide the opportunity for reporters via networks to do many things they could not do before. These can be summarized as follows:

a) Provides much greater content potential.

b) It allows non-linear narratives that can exceed the limits of time and editorial space.

c) It provides interaction with the audience before, during and after production.

d) It allows journalist to work in complex versatile flow network (Beckett, 2010: 5).

With the development of social networks, changes and transformations have taken place in traditional journalism practices. Now, journalists are taking advantage from social networks and ordinary people have become resources. The users as content producers are playing the role of journalists who give information and instruct others. People, in this case which is called as citizen journalism, participated in the news production processes and placed themselves in their place in areas where professionals could not involve in. 
When Web 2.0 represents an ideological and technological foundation, the user- generated content can be seen as the sum of all the ways in which people benefit from social media. This concept, which increased its popularity in 2005 , is often used to describe the various media content and formats created by public users and end users of something. User-generated content has three basic requirements. The first is that it has to be published on a public website or on a social networking site accessible to people. The other is to show a creative effort to a certain extent. Finally, it has to be created outside of professional routines and applications (Kaplan and Haenlein, 2010: 61). The most important point that allows the user to become a content producer is Web 2.0 and the social networks and portable devices it brings along. Together with these components, previously passive and consumer situated individuals have carried themselves to the position of agent and producer.

User-generated content comes from users who voluntarily distribute information or contribute to existing media, usually on the Web, such as restaurant ratings, wikis, and videos that may be a data useful to others. The use of this kind of content has been rapidly growing due to the fact that it has been relatively inexpensive to obtain partially in recent years. This process can also create the result of recognition of the content producer due to his/her contributions. (Krumm, Davies and Narayanaswami, 2008: 10)

User-generated Content, ignored by the foundations of the mainstream media or without their intervention, offers an overview to the real data coming from other people. Therefore, the feature of mainstream media which is being the only platform taken news and information from results in sharing it with social networks. While previously, media organizations sent their data to their target audiences the way they want, individuals who are strengthened with technology started to play an active role in determining the agenda and in evaluating right and wrong.

Social networking sites provide platforms for user-generated content, where citizens can publish their comments, photos, videos and more, online (Hermina and Thurman, 2008: 344). Diversification of these platforms causes varieties of user-generated content according to the specific area. The users are in constant production with tweets on Twitter, status updates for Facebook, sharing photos on Instagram and publishing videos for YouTube. The advice of a friend, the experience of an individual who has experienced any event, or the feedback of an individual who consumes a product, takes an important place in the point of guiding us. The existence of such a reference can be a reference center in terms of individual attitudes and behaviors. The existence of social networks has provided a basis for such production and sharing it with others. New digital technologies made users stronger and by doing so they provided the contents produced by them for the usage of other people.

Because users produce content they are now also called citizen journalists. The idea behind the citizen journalism is that people who have no professional journalism education create or reproduce media on their own or in collaboration with others or being able to use the modern technology devices and global distribution of the internet to control the authenticity (url3).

Previously, ordinary people being witnesses of the incidents, would tell the professionals who came to the scene what they saw. Nowadays due to phones that became smaller and portable enough to fit into our pocket, taking and sharing photos or videos with them, they are no longer only witnesses but became "journalists" who are transfering to broad masses. With the observations done by people being recorded and work which is done by broadcasting these began to overlap with journalistic activities.

For example, in an election period, a citizen with a smart phone and internet access, does not only vote but also tries to provide the security for the votes by observing the ballot box. Sharing situations which give an image of irregularities with a photograph or a video via networks, gives an opportunity to other people to know about the situation. This and situations similar to this are possible to reproduce. Because since smartphones and the internet have become parts of daily life, we have seen examples of many events. In Saddam Hussein's execution, the terrorist attacks in London, the events called Arab Spring, actions of İstanbul Gezi Park, sharing the content with others saved by the people who were there, show the point how an ordinary person let people know about the situation who are not there.

Jose van Dijck is pointing out that the Time Magazine referred to millions of anonymous internet users on its 2006 cover by showing "You" as the person of the year. Thus, it emphasizes to herald 
many volunteers who fill the platforms for user-generated content. Besides, it shows the uncertainty of who this participant from the digital environment is that the press shows respect to or who the "you" in the social networks are. The users ask the question of "is it a collective power to change the changing way of earth" that the magazine really wants to make us believe (2009:41).

\section{Crowd-Sourcing}

As a word Crowd-sourcing has been formed by combining the words "crowd" and "outsourcing" The aim of Crowd-sourcing is to bring people together from large masses and make a common business. The basis of this practice lies in a collective work of solidarity (Altunbaş, 2014: 50).

Use of mass resource extends beyond citizen journalism and encompasses a wide range of applications that use collective intelligence to make a choice in making news or to produce news, to control, to gather information. The information revealed by citizen journalists, increases the ability to know multiple dimensions of reality. However, all these pieces of knowledge require real-control, filtering and, above all, interpretation and analysis to create meaning. In these moments within an infinite flow of information, the added value capacity of professional journalists, to integrate information, to provide context and the capacity of inference by gathering information become part of the activity. (Haak, Parks ve Castells, 2012: 2928).

This case can provide to organizations, access to new ideas and solutions, deeper consumer engagement, creating together opportunities, optimization of tasks and lower costs. The Internet and social media brought organizations closer to their stakeholders, paved the way for new ways of collaborating and creating value as never before (url4). The basic concept behind this term is to use a large group of people for their ability, ideas, and participation to create content or help in the creation of content or products (url5).

In crowd-sourcing applications, mass is called for completing the online task by sending information related to research about a newspaper or a journalist. In mass-based journalism, people are invited to participate in various forms of journalism such as sending information, sharing ideas, and sending photographs (Aitamurto, 2016: 281). If we look at it this way, crowd-sourcing for journalism tells us the cooperation of media organizations, with an individual who becomes an usergenerator with technology, in producing news.

The basis for the current point is to provide interactive communication via digital platforms. By this means mutuality has been created, the way for data exchange has been paved and the basis for instant and quick transfers has been formed. Media organs have opened themselves to citizens and began to receive help from them. Crowd-sourcing provides transparency in news production while providing public involvement. However, as Aitamurto points out, the ones who are called "crowdsourcer" decide when, where and how the process will take place and how to use the input (2016: 283).

With crowd-sourcing, journalists have expanded their ways of accessing information. More documents were provided to send them. It has also brought advantages in terms of making comparisons and confirming the accuracy, showing the different aspects of events within a large number of information and documents. The dispatches of individuals, paved the way for journalists to measure which subjects that people are sensitive about, which subjects they are interested in.

\section{The Sample of Guardian's Crowd-Sourcing}

In 2019, the government in power and some MPs from opposition had the government pay their personal expenses and due to the emergence of this event caused big problems. After the emergence of this news by The Daily Telegraph newspaper, the file which contains these expenses, made public by the parliament.

The British Guardian newspaper shared the documents about the MPs' expenses with their readers on their website and asked them to help them analyze these documents. The shared data contained 700,000 documents in 5500 files, belonging to $646 \mathrm{MPs}$. This large set of information was both open and equally close. While documents which everyone can reach and shared in a transparent way show openness, because of the security, the censorship of MPs' addresses and correspondence 
with some public officials show privacy.This situation, which is not enable a single person or an institution to be lifted, led the Guardian newspaper to receive direct support from its readers. Developed a special application for this topic and by using the website, citizens will be able to look directly at the records of their MPs or any member and will be able to share their opinions. This is exactly what the newspaper asked for help. He asked his readers to comment on the MPs' expenses, to highlight their interests and to share posts about the interestingness of receipts they search (url6). June 18, 2009 after the requested information, document and analysis comments from the Thursday readers, on the period until the date of September 18, 2019 the 500,000 documents have been uploaded to the Guardian newspaper's website. After analyzing these documents, the newspaper again presented the documents to their readers by dividing categories as in the names of MPs, parties, how many forms are sent and the expenses on their website. It again showed that the convenience to interact by asking a question like "What else do you want to know?" (url7).

\begin{tabular}{|l|l|l|}
\hline & $\begin{array}{l}\text { Traditional News } \\
\text { Production }\end{array}$ & $\begin{array}{l}\text { News Production with Crowd- } \\
\text { Sourcing }\end{array}$ \\
\hline News Producer & Journalists & Journalists + Related Individuals \\
\hline Access to News' Source & Limited & Broad \\
\hline News Perspective & $\begin{array}{l}\text { Approaching at certain } \\
\text { angles }\end{array}$ & See different perspectives \\
\hline Time spent gathering news & Much & Little \\
\hline Content production cost & Much & Little \\
\hline $\begin{array}{l}\text { Devices to take information from } \\
\text { readers }\end{array}$ & Phone, Letter, Fax & $\begin{array}{l}\text { Websites, applications, social } \\
\text { media shares and feedbacks, mails }\end{array}$ \\
\hline The position of the reader & Passive & Active \\
\hline $\begin{array}{l}\text { The relationship between the reader } \\
\text { and journalist }\end{array}$ & One-sided & Interactive \\
\hline
\end{tabular}

Table 1: Comparison of traditional news production to news production with crowd-sourcing

Simon Rogers, a former news and data editor at The Guardian, says in an interview that they sometimes received too many files, reports, and statistics, and also received some documents that are inaccessible and in poor format, but none of them could be helpful.

Therefore, at this point, it is stated that crowd-sourcing may help. They also have many documents about the MPs' expenses but at the same time they have many readers and for this reason, it is stated that it means lots of people. He therefore said that they could not find a better way other than to open the task to readers and share with them. It is pointed out to the importance of the issue which we need people's help in this kind of tasks, it is because of that they are into the subjects that people are really interested in, they want to take their time to be with them, and it says that it causes the important data traffic which is sent to themselves. (Bouchart, 2012: 137-138).

As can be seen from this example, news production has been continuously updated by the networks that are not one-sided and stagnant, fed by the user-generated content, at the same time masses have been used as the source and the framework of the news has been formed by getting help in cooperation with them.

\section{Conclusion}

The Internet and the innovations it have brought have been the herald of a new world for people. In particular, Web 2.0 and following the social media, united with user-friendly devices, have completed the establishment of "global village" where millions of people come together. This new era has provided significant support for the construction of structures that are rising through networks.

The fact that the Internet, television, radio and many other features of the newspaper are inclusive, has enabled individuals to access news, entertainment and information from one source 
without using different tools. Newspapers have also taken their place with their web sites and social media accounts. With enriched content, instant updates, commentary, sharing and liking possibilities users have become more attractive to users. The position of a one-sided news has been moved to the point, a more active role and a producer at the same time where information flow exists and the position of the reader as a passive consumer and where there is an interaction.

In addition to traditional media, the emergence of network-based journalism in the light of technological developments seems to be a normal result. Since humanity has existed, every production has produced its own consequences. In this regard, it is necessary to look at the network journalism formed by today's conditions. It is useful to re-read and review the practices of journalism that have been applied before. Because the job is journalism, but it is necessary to add new features, to update existing ones, and to remove applications that are not functional. For example, the news format for a television or newspaper varies when presented from networks to the user. The space and time limit in traditional media organs have been eliminated, allowing for the simultaneous use of many contents. It is even easier to update news and deliver new news to the user in the fastest way. However, this issue has caused new problems in terms of verification.

Yet another issue is the point where journalists will take part in their own or corporate identity. It allows journalists to share their news to their followers through networks, to measure responses, to interact with them, to receive feedback and to share information at the same time. On the other hand, they have to pay attention to the issue of not to affect negatively the image of the places where they are affiliated with the salary. Doing business under the roof of an institution may cause certain limits to the sharings in their individual accounts.

The implementation of network-based journalism activities on web sites, blogs and social media has paved the way for the active participation of users in these processes. Not only did they follow the news, but also started to produce their own content by adding photos or videos they took. Usergenerated content is created not only in terms of contribution to the news but also in the places where the professionals cannot enter or reach. In this way, users contribute to the news production by benefiting from the technology and by determining the agenda in digital media and feeding the main stream with their production.

Another consequence of the user generated content is that it enables to get information from the source which is given different ways or the main stream ignores. The supervisory and observer role of the media is sometimes unable to be the fourth force by its patronage structure, sometimes by political will and sometimes by different kind of interests. Individuals at these points are being a source for news production and producing their own content will remove the barriers to other people getting the right information. Thus, the hegemony of traditional media in news production and distribution was broken by the emergence of these alternative events. Traditional media tools have now to be shared with ordinary citizens.

The emergence of the concept of "citizen journalist" where came to the point of today's technologies shows us the power of ordinary people. Media organizations use the user-generated content in the form of crowd-sourcing and use it in news production for network-based or mainstream. People began to contribute to the organizations by sending information and documents. Press organizations can get support and interaction by opening the issue to their readers at points that they think they cannot be overcome by themselves. In other words, ordinary people and newspapers cooperated to create the process of forming the news together.

As seen in The Guardian example, the editors in the channels broadcasting from networks had to fulfill the requirements of the platforms they were reporting. The news has been actively updated since it is not a constant information transfer, and the changes are immediately transferred and open to feedback. Journalists started to use these places as resources and interacted with readers / users and started to integrate the content which they produced. The size of the incident on the issue of MPs' expenses has led to the development of cooperation among those who produce and read the news and with the help of people, the newspaper had the opportunity to handle the event in a broader context.

In the cases where the consequences of a large number of the citizens of the country will affect a significant number of citizens, newspapers, will have positive results when they are in cooperation with individuals. The hardships of newspaper and journalists about not be able to obtain any information and not reaching every point will be ensured to open. Detecting points that can be overlooked will bring new perspectives to the news. It will enable the event to be presented close to all 
available details. It will also increase its belonging to the news source followed by the reader and will strengthen the link between the reader and the newspaper.

Although the changes and transformations that have occurred have differences in access to news and information, people has not changed in terms of the need of knowing. The history of mankind has always maintained the desire to learn by means of different tools and the different means offered by those vehicles. Today, this situation has been moved to the virtual environment via the internet and networks have created their own parameters. These parameters cause the media to share the power in the news production with the society.

\section{References}

[1] Altunbaş, F. (2014). Soysal medyaya genel bir bakış. Müge Demir (Ed.) Yeni medya üzerine vol. 2. (p. 45-63). Konya: Literatürk

[2] Bouchart, M. (2012). Crowdsourcing data at the Guardian datablog. Jonathan Gray, Liliana Bounegru ve Lucy Chambers (Ed.) The data journalism handbook. (p. 137-139). California: O'Reilly Media

[3] Gündüz, U., Pembecioğlu, N. (2013). Bilgi kaynağı olarak sosyal ağlar ve sosyal medya. [4] Müge Demir (Ed.) Yeni medya üzerine (p. 311-339). Konya: Literatürk

[5] Kara, T. (2012). Sosyal medya kobiler için bir fırsat mı? Facebook ve linkedln üzerinden bir inceleme.

[6] Kara, T. ve Özgen, E. (Ed.). Sosyal medya akademi. (p. 113-129). İstanbul: Beta Yayıncılık.

[7] Alfred H., \& Neil, T. (2008). "A clash of cultures: The integration of user-generated content within professional journalistic frameworks at British newspaper websites", Journalism Practice, 2(3), p. 343-356

[8] Andreas M. K., \& Michael H., (2010). "Users of the world, unite! The challenges and opportunities of social media", Business Horizons, 53, p. 59-68.

[9] Bregtje V. D. H., Parks, M., \& Castells, M. "The future of journalism: networked journalism", International Journal of Communication, 6, 2012, p. 2923-2938

[10] Beckett, C., (2010). "The value of networked journalism", The value of networked journalism, London: LSE, 11 June 2010, p. 1-17

[11] M. Boyd, M., D., \& Ellison, N., B. (2008). "Social network sites: definition, history, and scholarship", Journal of Computer-Mediated Communication, 13, p.210-230

[12] Krumm, J., \& Davies, N. (2008). Chandra Narayanaswami, "User-generated content", IEEE Pervasive Computing, 7(4), p. 10-11

[13] Dijck, J. V. (2009). "Users like you? Theorizing agency in user-generated content", Media Culture Society SAGE Publications, 31(1), p. 41-58

[14] Özçağlayan, M., \& Uyanık, F. (2010). "Sosyal medya ve gazetecilik", İstanbul: Marmara Üniversitesi, 28-30, p. 60-71

[15] Naik, U., \& Shivalingaiah, D. (2009). "Comparative study of Web 1.0, Web 2.0 and Web 3.0" 6th International Caliber, Allahabad: University of Allahabad.

[16] Aitamurto, T. (2016). "Crowdsourcing as a knowledge-search method in digital journalism", Digital Journalism, 4:2, p. 280-297

[17] URL 1: "Internet”, 2018, https://bit.ly/2K6S4Kd [14.11.2018]

[18] URL 2: Getting, B. "Basic definitions: Web 1.0, Web. 2.0, Web 3.0", https://bit.ly/2kkZ3GJ [14.11.2018]

[19] URL 3: Glaser, M. "Your guide to citizen journalismhttps://bit.ly/1RDuzXL [12.11.2018]

[20] URL 4: "What is crowdsourcing", 2018, https://bit.ly/2kPUIAZ [12.11.2018]

[21] URL 5: Goodrich, R. "What is crowdsourcing", https://bit.ly/2kEXiVd [12.11.2018]

[22] URL 6: "How to crowdsource MPs' expenses" https://bit.ly/2ylf9Pe [26.01.2019]

[23] URL7: "MPs' expenses: what you've told us. So far" https://www.theguardian.com/news/datablog/2009/sep/18/mps-expenses-westminsterdata-house-of-commons [01.02.2019] 